\title{
FROM COMPLEX EVOLVING TO SIMPLE: CURRENT REVISIONAL AND ENDOSCOPIC PROCEDURES FOLLOWING BARIATRIC SURGERY
}

\author{
Evolução do complexo para o simples: procedimentos revisionais e endoscópicos após cirurgia bariátrica \\ Ricardo ZORRON ${ }^{1}$, Manoel Passos GALVÃO-NETO², Josemberg CAMPOS ${ }^{3}$, Alcides José BRANCO4, \\ José SAMPAIO ${ }^{4}$, Tido JUNGHANS ${ }^{5}$, Claudia BOTHE ${ }^{5}$, Christian BENZING ${ }^{1}$, Felix KRENZIEN ${ }^{1}$
}

From the ${ }^{1}$ Center for Innovative Surgery (ZIC), Department of General, Visceral and Transplant Surgery, Campus Virchow Klinikum and Department of General, Visceral, Vascular and Thoracic Surgery, Campus Mitte, Charité-Universitätsmedizin Berlin, Berlin, Germany; ${ }^{2}$ Department of Bariatric Endoscopy, Gastrobeso Center, São Paulo, SP, Brazil; ${ }^{3}$ Department of Surgery, University Federal of Pernambuco, Recife, $\mathrm{PE}$, Brazil; ${ }^{4}$ Department of Surgery, CEVIP Center, Curitiba, PR, Brazil; ${ }^{5}$ Department for General, Visceral, Thorax and Vascular Surgery, Klinikum Bremerhaven Reinkenheide, Bremerhaven, Germany

HEADINGS - Bariatric surgery. Obesity. Metabolic surgery. Operative technique. Procedure selection. Gastric bypass. Gastric banding. Endoscopy.
ABSTRACT - Background: Roux-en-Y gastric bypass (RYGB) is a standard therapy in bariatric surgery. Sleeve gastrectomy and gastric banding, although with good results in the literature, are showing higher rates of treatment failure to reduce obesity-associated morbidity and body weight. Other problems after bariatric may occur, as band erosion, gastroesophageal reflux disease and might be refractory to medication. Therefore, a laparoscopic conversion to a RYGB can be an effective alternative, as long as specific indications for revision are fulfilled. Objective: The objective of this study was to analyse own and literature data on revisional bariatric procedures to evaluate best alternatives to current practice. Methods: Institutional experience and systematic review from the literature on revisional bariatric surgery. Results: Endoscopic procedures are recently applied to ameliorate failure and complications of bariatric procedures. Therapy failure following RYGB occurs in up to $20 \%$. Transoral outlet reduction is currently an alternative method to reduce the gastrojejunal anastomosis. The diameter and volume of sleeve gastrectomy can enlarge as well, which can be reduced by endoscopic full-thickness sutures longitudinally. Dumping syndrome and severe hypoglycemic episodes (neuroglycopenia) can be present in patients following RYGB. The hypoglycemic episodes have to be evaluated and usually can be treated conventionally. To avoid partial pancreatectomy or conversion to normal anatomy, a new laparoscopic approach with remnant gastric resection and jejunal interposition can be applied in non-responders alternatively. Hypoglycemic episodes are ameliorated while weight loss is sustained. Conclusion: Revisional and endoscopic procedures following bariatric surgery in patients with collateral symptomatic or treatment failure can be applied. Conventional non-surgical approaches should have been applied intensively before a revisional surgery will be indicated. Former complex surgical revisional procedures are evolving to less complicated endoscopic solutions.

\section{Correspondence:}

Ricardo Zorron

E-mail: ricardo.zorron@charite.de,

rzorron@gmail.com

Financial source: none

Conflicts of interest: none

Received for publication: 16/08/2016 Accepted for publication: 02/10/2016

DESCRITORES: Cirurgia bariátrica. Obesidade. Cirurgia metabólica. Técnica operatória. Seleção procedimento. Bypass gástrico. Banda gástrica. Endoscopia.
RESUMO - Racional: Bypass gástrico em Y-de-Roux (BGYR) é procedimento padrão em cirurgia bariátrica. Gastrectomia vertical e banda gástrica, embora com bons resultados na literatura, estão mostrando taxas mais elevadas de insucesso no tratamento para reduzir a morbidade associada à obesidade e peso corporal. Outros problemas pós-operatórios podem ocorrer, como a erosão da banda, e doença do refluxo gastroesofágico refratária à medicação. Portanto, conversão laparoscópica para BGYR pode ser alternativa eficaz, desde que indicações específicas para a revisão sejam cumpridas. Objetivo: Analisar os nossos dados e os da literatura sobre procedimentos bariátricos revisionais para avaliar melhores alternativas para a prática atual. Métodos: Foram efetuados experiência institucional e revisão sistemática da literatura sobre cirurgia bariátrica revisional. Resultados: Procedimentos endoscópicos estão sendo aplicados recentemente para melhorar a falha e complicações de procedimentos bariátricos. Falha terapêutica após BGYR ocorre em até $20 \%$. A redução transoral é atualmente um método alternativo para reduzir a anastomose gastrojejunal. A gastrectomia vertical pode apresentar aumento de volume e do diâmetro do pouch, o qual podem ser reduzidos por meio de sutura total endoscópica longitudinal. Síndrome de dumping e episódios de hipoglicemia grave (neuroglicopenia) podem estar presentes nos pacientes com BGYR. Os episódios hipoglicêmicos devem ser avaliados e geralmente podem ser tratados convencionalmente. Para evitar pancreatectomia parcial ou conversão à anatomia normal, uma nova abordagem laparoscópica com ressecção do remanescente gástrico e interposição de jejuno, pode ser aplicada como alternativa em não-respondedores. Episódios de hipoglicemia melhoram, enquanto a perda de peso é mantida. Conclusão: Procedimentos revisionais endoscópicos podem ser aplicados após cirurgia bariátrica em pacientes com sintomas colaterais ou na falha do tratamento. Abordagens convencionais não-cirúrgicas devem ser aplicadas intensivamente antes que uma operação revisional seja indicada. Antigos procedimentos cirúrgicos revisionais complexos estão evoluindo para soluções endoscópicas menos complicadas. 
cardiovascular disease and thus has enormous consequences for the health system itself.

Bariatric and metabolic surgical procedures are superior compared to conservative multimodal therapies for morbid obesity ${ }^{2,3}$. For example, type 2 diabetes mellitus, hypertension, dyslipidemia and sleep apnea syndrome are successfully treated in most cases ${ }^{4}$. This has led to the acceptance of bariatric surgery, which has increased rapidly worldwide in the last 20 years. In 2003 approximately 150.000 bariatric procedures were performed, and in 2013 already it turned to be around 470.000 interventions ${ }^{5}$. The success of bariatric surgery is defined in terms of reduction in obesity-associated morbidity and a successful weight reduction ${ }^{6}$. Roux-en-Y gastric bypass (RYGB) is the gold standard and the most commonly performed bariatric surgery with a relative proportion of approximately $45 \%{ }^{5}$, although laparoscopic sleeve gastrectomy (LSG) just have gained the position of most performed bariatric procedure in many countries.

The results of bariatric surgery are convincing, although some of the patients have a regain in body weight or the achieved weight loss is insufficient. The etiology of such socalled treatment failure is multifactorial and may causally be patient-dependent (nutrition, metabolism, hormonal status, physical activity) and technical-dependent factors (complications, type of procedure) $)^{7}$. The weight regain in initial normal course is typically associated with the recurrence of the comorbidities.

The aim of this article was to review and analyze the technical aspects of bariatric conversion procedures and endoscopic revision procedures introduced which can be used in therapy fails or when complications occur.

METHOD

This study consisted of a report on our institutional experience with revisional bariatric surgery and a systematic review of the literature based on reference analyses retrieved from current databases such as PubMed, Lilacs and SciELO. The search strategy was defined by terms related to [bariatric surgery] in combination with [revisional surgery] as well as [surgery complications] in English, Portuguese or Spanish language.

\section{RESULTS}

\section{Rationale of revisional bariatric surgery}

The success of bariatric surgery is often defined by the achieved weight loss caused by the\% EWL (excess weight loss). It can be specified by:

$\% \mathrm{EWL}=$ (preoperative body weight - current body weight)/ (preoperative body weight - ideal body weight) x 100

A successful bariatric surgery was defined by Brolin et al. with a $\% E W L \geq 0 \%$. Furthermore, the achieved weight loss was classified by Reinhold criteria ${ }^{9}$, been modified by Christou et al. 2006, and now find a wide clinical application ${ }^{10}$ : a) incompetent weight loss if $\mathrm{BMI}>35 \mathrm{~kg} / \mathrm{m}^{2} ;$ b) good weight loss when $\mathrm{BMI}=30$ to $35 \mathrm{~kg} / \mathrm{m}^{2}$; c) excellent weight loss if $\mathrm{BMI}<30 \mathrm{~kg} / \mathrm{m}^{2}$

Current guidelines or consensus items of the respective professional societies for performing bariatric conversion procedures are not available. However, this can be indicated in clinical practice by the following characteristics: a) incompetent weight loss $\left(\mathrm{BMI}>35 \mathrm{~kg} / \mathrm{m}^{2}\right)$; b) rebound weight gain $\left(\mathrm{BMI}>35 \mathrm{~kg} / \mathrm{m}^{2}\right)$; and c) recurrence of a metabolic disorder or complication of the initial process (acute and chronic). Before a possible conversion engaging conservative treatment methods is essential. Furthermore, they should be performed over a longer period, in general longer as two years, before the indication for surgical revision is made. Current guidelines for the timing of the implementation of a conversion procedure are not well delineated ${ }^{11,12}$ so that restraints of the health insurance companies may occur.

Audit procedures were performed in accordance with the German Bariatric Surgery Registry (GBSR, prospective quality assurance study for the surgical treatment of obesity at the Institute of Operational Medicine at Otto von Guericke University, Magdeburg) in $8.6 \%$ of cases $^{11}$. In $7 \%$ conversion operations were carried out ${ }^{11}$, the lack of weight loss or weight regain were the main reasons ${ }^{13}$.

\section{Conversion of sleeve gastrectomy to RYGB}

LSG is performed more frequently in recent years. However, few long-term data show often insufficient weight reduction $3,14,15$. The initial weight loss after LSG is given as over $50 \%$ (EWL), but it takes up to $20 \%$ of cases of regaining weight ${ }^{16,17}$. In addition in a LSG, symptoms of gastroesophageal reflux may occur and are usually refractory to medical therapy ${ }^{18}$. In both cases, a conversion process can be performed ${ }^{19}$. The conversion of a LSG to a RYGB is the method of choice and reliably causes a new weight reduction at a slightly increased rate of complications ${ }^{20-22}$. The mortality of the conversion to RYGB is less than $1 \%{ }^{21,23}$.

\section{Technical aspects}

The conversion to RYGB can be performed laparoscopically. In most cases, an extended adhesiolysis between the stomach and liver is necessary. After retraction of the liver, the omentum minus is dissected and the stomach tube mobilized toward diaphragm. The stomach tube is divided horizontally by a stapler (Figure 1). The vessels and nerves along the lesser curvature are preserved, so that the blood flow to the rest of the stomach remains and maintaining pylorus function. In cases in which the gastric tube is already dilated, a further reduction of the pouch is necessary. Another stapler cartridge truck $(60 \mathrm{~cm})$ is placed vertically in order to reduce the new pouch laterally. Resection of the remaining excluded stomach is not usually necessary, except when the blood support or vagus nerve are damaged. ${ }^{24}$. After this, the completion of RYGB is carried out in a tipical way.

\section{Conversion of gastric band to RYGB}

The laparoscopic adjustable gastric band shows in the initial period low perioperative morbidity ${ }^{25}$. In long term, however, increased complication rates including gastric perforation, band dislodgement, band migration, gastroesophageal reflux disease or endoluminal gastric band erosion are described ${ }^{26-28}$. Endoscopic gastrointestinal band extraction is preferable than minimally invasive or surgical extraction ${ }^{29}$. However, this engagement is not always feasible and technically demanding. Nevertheless, inadequate weight loss after a gastric band is the most common cause to perform a conversion to LSG or RYGB ${ }^{30}$. The conversion of the laparoscopic adjustable gastric band for RYGB shows good clinical results ${ }^{10,33}$. The weight loss and permanent weight reduction is comparable to the primary RYGB, although the indication is provided due to insufficient weight reduction or due to gastric banding associated complication. The largest study of the conversion from the gastric band to RYGB $(n=642)$ had a mortality of $0 \%{ }^{34}$. Complication rate was $9.7 \%$, with $3.6 \%$ of patients having serious complications. The long-term results (observation period of 10 years) are similar to the results of a primary RYGB. The conversion of the gastric band to RYGB can be done one-stage or two-stage. In the two-stage conversion the first step is the removal of the band and subcutaneous port. In a second procedure the gastric bypass is applied. In this regard, the data are controversial and neither of the two approaches has a clear advantage on. The advantages of the one-stage process, the reduced operative time, length of hospital stay and economic factors are given. 


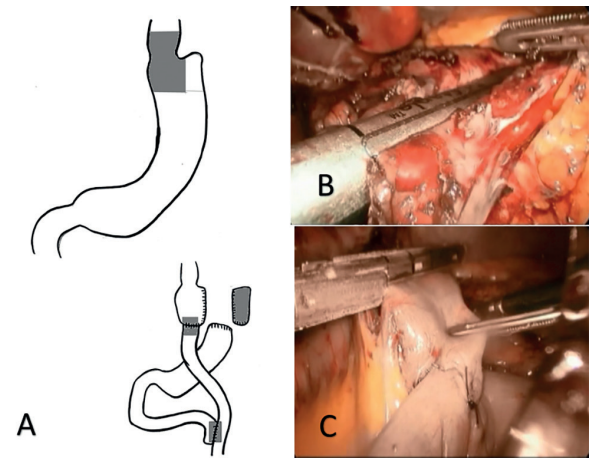

FIGURE 1 - Conversion from laparoscopic sleeve gastrectomy (LSG) to RYGB: A) schematic illustration of the conversion where LSG is cut horizontally with a linear stapler, preserving the blood vessels and, in some cases, reduction of the pouch is indicated, for dilated sleeves; B) linear stapler is set horizontally to delineate the pouch formal RYGB is performed; C) the afferent loop of the performed gastrojejunal anastomosis is cut by a linear stapler to form the Y-Roux.

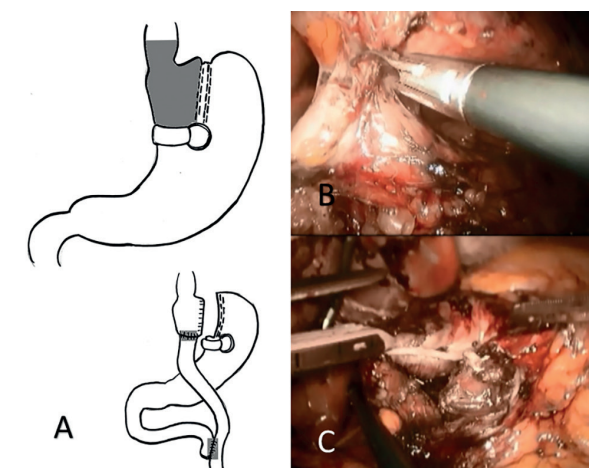

FIGURE 3 - Conversion from vertical stapled gastroplasty (Mason) to Roux-enY-gastric bypass: A) schematic illustration of the conversion with the stapling line to perform the pouch is horizontally set, without crossing the previous vertical gastroplasty; B) adhesions in the region of the gastroplasty are solved, to identify the ring, a $45 \mathrm{~mm}$ stapler is set horizontally and a further stapler $(60 \mathrm{~mm})$ is also set vertically (medial or at the Mason gastroplasty) to allow distal flow, if the former pouch is not resected; the ring can be or not extracted, depending on the position of the new pouch; $\mathrm{C}$ ) construction of the pouch using 45 stapler and the pouch is anastomosed to the alimentary limb, and a formal RYGB is performed.

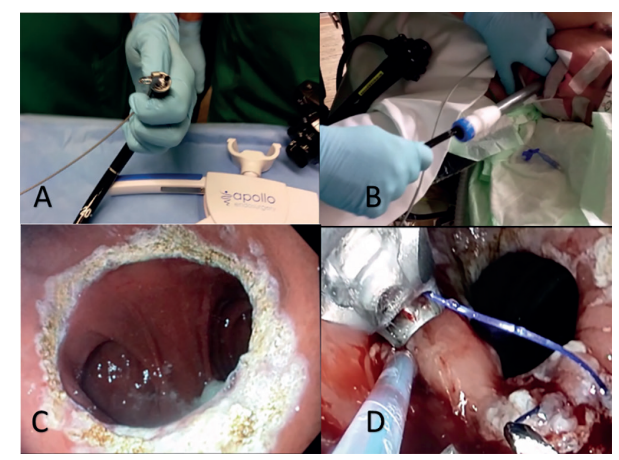

FIGURE 5 - Endoscopic revision of RYGB: A) the transoral reduction of the gastrojejunal anastomose after RYGB (transoral outlet reduction/TORE) is performed endoscopically, using a special full-thickness suture device (Apollo Overstich ${ }^{\circledR}$, Austin, TX, USA); B) a special overtube is inserted to prevent esophageal damage; $\mathrm{C}$ ) the enlarged gastrojejunal anastomosis (around $5 \mathrm{~cm}$ ) is prepared for sutures using Argon beamer; D) the dilated outlet anastomosis is effectively reduced to less than $9 \mathrm{~mm}$ through Overstich ${ }^{\circledR}$ sutures.

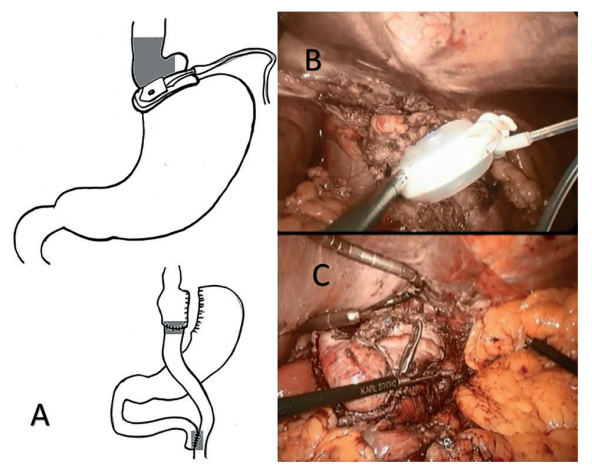

FIGURE 2 - Conversion of a laparoscopic adjustable gastric band to RYGB: A) schematic illustration of the conversion where the linear stapler is set proximally to the scarred tissue of the former band, when possible; $\mathrm{B}$ ) adhesions and scars to gastric wall are solved; $C$ ) the pouch is performed through a horizontal and a vertical stapler, and formal RYGB is performed.
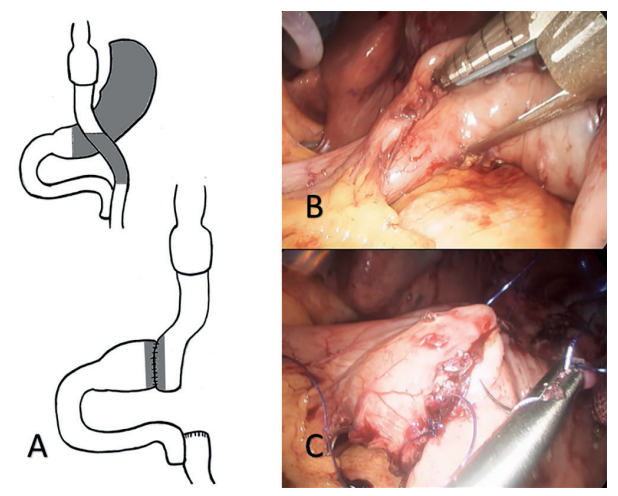

FIGURE 4 - Conversion from RYGB to jejunal interposition with subtotal gastrectomy - Branco switch: A) schematic illustration of the conversion for therapy of severe hypoglycemia after RYGB; the primary objective is transforming the RYGB and restoring the continuity to the duodenum through ajejunal interposition and subtotal gastrectomy; B) performing a pylorus-preserving gastrectomy at $2-4 \mathrm{~cm}$ of remaining antrum and, finally, the alimentary limb is resected at 20 $\mathrm{cm}$ from the gastrojejunal anastomosis till the $\mathrm{Y}$-Roux anastomosis; C) the $20 \mathrm{~cm}$ remaining alimentary limb becomes a handsewn anastomosis to the rest of the antrum and the $\mathrm{Y}$-Roux is closed by a stapler to finalize the resection of the alimentary limb.

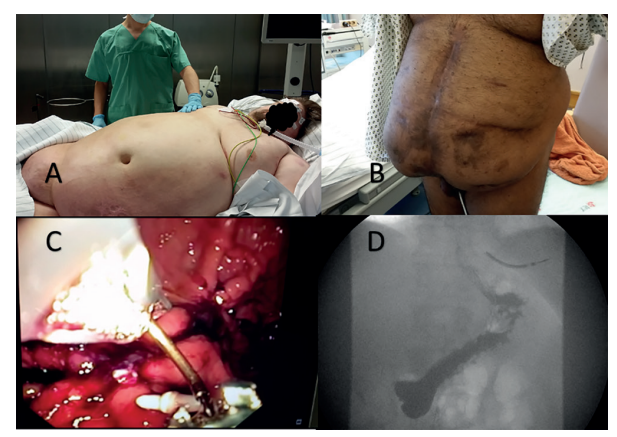

FIGURE 6 - Endoscopic sleeve gastroplasty (ESG): A) novel indications for primary endoscopic sleeve gastroplication, as a first step in high risk patients for preparation for a surgical second step in 9-12 months; BMl=72 (315 kg) with respiratory insufficiency and tracheostomy; $B$ ) as a primary procedure in patients with giant hernia and adhesions; in this patient, laparoscopic SG was aborted due to adhesions, and ESG was indicated; C) the performance of ESG as a primary bariatric procedure is set through consecutive full-thickness sutures from the incisura angularis to proximal; the sutures are interrupted, so the gastric secretion and food can have free transitbetween the gastroplasty; D) postinterventional radiologic study after ESG. 
In addition, the gastric band can be used for orientation of the pouch construction. In the two-stage process after band removal there is a waiting period of 2-6 months to apply the gastric bypass as a second step. In summary, similar complication rates are listed, even though the evidence is very inhomogeneous and no final statement can be made in systematic reviews of both methods ${ }^{10,33}$. Moon et al. showed that the conversion of a gastric band to sleeve gastrectomy or RYGB comprises comparable results regarding weight loss and the rate of complications ${ }^{35}$.

\section{Technical aspects}

The patient can be explored laparoscopically and adhesions (especially between the stomach and liver) are dissected. The band tube is separated from the gastric part of the band and extracted later with the port through a trocar. The gastric band and the surrounding capsule are dissected with scissors or the ultrasonic scissors. Before the actual conversion is done, endoscopy is performed to rule out a possible erosion of the gastric band. In the event of a defect, the elective conversion must be stopped and postponed until the complete healing. The construction of a pouch (Figure 2), avoids the scarring tissue and preferable distal to the former gastric band. The tissue in the area of the former gastric band is usually very vulnerable and not suitable for anastomosis. Following, the other regular steps of RYGB are performed. to RYGB

Conversion of vertical banded gastroplasty (Mason)

The vertical gastroplasty in 1982, described by Mason ${ }^{31}$, was for years the bariatric method of choice ${ }^{32}$. Initial weight loss is mostly successful ${ }^{33}$ although the patients may develop complications and have in the long term insufficient weight reduction ${ }^{12}$. The surgical revision is often combined with conversion to bariatric procedures, being to RYGB the most common. Mortality is related to be less than $1 \%{ }^{34,35}$. The complication rates occur at a frequency of 9-19\% ${ }^{34-37}$. Patients with a vertical banded gastroplasty, which must be revised surgically without carrying out a conversion to RYGB, have disappointing results and will be revised again in $50 \%$ of cases. In contrast, there is a significantly lower rate of rerevisions (under $5 \%$ ), if simultaneously RYGB conversion is performed as the first revisional procedure ${ }^{34,38,39}$. Overall, the conversion of vertical gastroplasty to RYGB is useful, although it is associated per se with increased mortality and is inferior to other bariatric procedures.

\section{Technical aspects}

The patient is submitted to an exploratory laparoscopy and adhesions is solved (especially between the stomach and liver). The left lobe is fixed by a retractor. The pouch region is dissected. A linear stapler $(45 \mathrm{~mm})$ is set horizontally without crossing the vertical line of the former vertical gastroplasty (Figure 3). The band is often not removed and remains in the existing position in the patient ${ }^{40}$. Another stapler $(60 \mathrm{~mm})$ is placed medial of the vertical gastroplasty to ensure an outflow of the old pouch distally. Another option is the resection of the ring and use the previous vertical staple line as the new pouch. All staple lines can be oversewn with absorbable suture. Following, a standard RYGB is typically performed.

\section{Conversion of RYGB to jejunal interposition with resection} of excluded stomach and alimentary limb (Branco switch)

In a few cases, after creating a RYGB, severe hypoglycaemia with neuroglycopenia (NIHHPB - non-insulinoma hyperinsulinemic hypoglycaemia post-bypass) can occur. The prevalence in the literature shows a high variety and is in some study about $1 \%{ }^{41,42}$. Recently published study $(n=1206)$ showed cumulative 5 -year prevalence of $13.3 \%{ }^{43}$. Patients were included only without preoperative diabetes before the original operation and were classified according to the Edinburgh hypoglycemia scale. One reason for variety in the occurrence in different databases is attributed to an insufficient medical detection of hypoglycemic episodes.

Patients with severe hypoglycemia are hospitalized and need to receive adequate diagnosis ${ }^{44}$. This includes a detailed medical history (temporal relationship between symptoms and food intake) including the detection of the current medication (interference with beta-blockers, ACE inhibitors, antibiotics, angiotensin receptor blockers). Furthermore, hormone levels (cortisol, somatropin, insulin-like growth factor, thyroid hormones), heart, kidney and liver function, should be checked which can cause hypoglycemia. Functional mixed-meal tolerance test ${ }^{44}$ is preferable to the oral glucose tolerance test, but it is difficult to compare among series. For the possibility of insulinoma, neuroendocrine tumors imaging is recommended. In individual cases, hyperplastic beta cells can be selectively stimulated and localized by calcium gluconate ${ }^{45}$.

The primary recommended treatment is conservative, with dietetic measures and/ $r$ medication. A few patients do not respond to these therapies, and can optionally be treated surgically. Various methods are reported in the literature, although all have a very small number of cases. The restoration of the RYGB anatomy through a gastrogastrostomy including the resection of the alimentary loop ${ }^{46}$ or even the placement of a gastrostomy in the distal stomach, could treat the NIHHPB in selective cases ${ }^{47}$. The mechanism of such interventions is the hypothesis that the transport of food through the alimentary loop excluding the duodenum is responsible for NIHHPB. Furthermore, a so-called nesidioblastosis hypertrophy of beta-Langerhans cells of the pancreas in adults - is presumed to be installed in the pancreas, which is associated with an autonomous insulin secretion. The exact pathological mechanism is not fully understood ${ }^{48}$. In severe cases with refractory neuroglycopenia episodes and severe hypoglycemia, partial or total pancreatic resection have been considered ${ }^{49,50}$. Alternatively, the occurrence of NIHHPB can currently be treated by a Branco switch procedure. The technique was developed by the group of Alcides Branco, from Curitiba, Brazil ${ }^{51}$. The goal of the procedure is to restore the duodenal continuity, resection of most of the alimentary limb and excluded stomach, so that the passage of food through the duodenum allows for reduction of delayed insulin and pancreatic secretion. By still maintaining malabsortion and restriction, the desired weight reduction is still guaranteed.

So far, nine patients in our study have been laparoscopically operated by the Branco switch technique due to severe hypoglycemic episodes ${ }^{51}$. Postoperative normal pre- and postprandial glucose and insulin levels were measured. Hypoglycemic episodes stopped in all patients and were therefore treated successfully. The BMI was $32.5 \mathrm{~kg} / \mathrm{m}^{2}$ before and $29.9 \mathrm{~kg} / \mathrm{m}^{2}$ six months after the Branco switch. Ulcers, dumping and other complications have not occurred in the mean observation period of two years.

The medical evidence is low in endoscopic and laparoscopic procedures for treatment of NIHHPB that are conducted in individual specialized centers. The TORE procedure (transoral endoscopic outlet repair of G-J anastomosis), by reducing the diameter of the gastroenteroanastomosis, is showing good results for treatment of dumping syndrome and weight regain after RYGB.

\section{Technical aspects}

The conversion procedure can be performed laparoscopically. Mobilization of the stomach is done and the antrum is stapled close to the pylorus $(2-4 \mathrm{~cm})$ to perform partial gastrectomy. The alimentary jejunal loop is resected until $20 \mathrm{~cm}$ to the G-J anastomosis, which remains intact. The 20 $\mathrm{cm}$ length alimentary jejunum is then anastomosed to the antrum close to the pylorus. The gastrojejunal anastomosis 
is performed handsewn (Figure 4). The former Y-anastomose is also closed (resection of the alimentary limb) by a staple. A total of four or five trocars are set to RYGB conversion to Branco switch. A novel vacuum liver retractor can be used to avoid an additional trocar ${ }^{52}$

In general a larger diameter should be used $(4.2 \mathrm{~mm})$ because the gastric wall can be thickened by scarring in the use of stapling devices. Due to the increased complication rate of revisional surgery, the use of large stapler charges (black or green) and intra-abdominal drainage is recommended ${ }^{11}$.

\section{Endoscopic revisional procedures}

Apollo transoral reduction of gastrojejunal anastomose (Trans oral outlet reduction/TORE)

Weight regain occurs up to $20 \%$ of cases after RYGB ${ }^{53,54}$. For these patients, novel endoscopic methods can be used to reduce the weight. The transoral reduction in the diameter of gastrojejunal anastomosis (TORE) is performed endoscopically. A special suture device (Apollo Overstich ${ }^{\circledR}$, Austin, TX, USA) is a full-thickness endoscopic suture, laterally set so that the diameter and thus the output of the distal stomach pouch is reduced (Figure 5) $)^{55,56}$. The method has a restrictive effect on food intake and can cause renewed weight loss in recent series and in our experience. The pre-interventional evaluation is important to evaluate whether the gastric pouch or the gastrojejunostomy are dilated, as only with enlarged diameter the use of TORE technique is indicated. The patient can be discharged in the early post-interventional period $(<24 \mathrm{~h})$ after a short monitoring. In the largest prospective study $(n=150)$ a reduction in the EWL of $19 \%$ was achieved after an observation period of three years ${ }^{57}$. No severe complications occurred, although abdominal pain (4\%), hematemesis/melena (3.3\%) and nausea (2\%) were observed. The diameter of the gastrojejunal anastomosis was reduced from a mean of 24 $\mathrm{mm}$ to $9 \mathrm{~mm}(\mathrm{p}<0.05)$.

\section{Apollo endoscopic sleeve gastroplasty/ESG}

The endoscopic system for producing sleeve intragastric plication without the need for an abdominal incision was first published in $2013^{60}$. This intervention is indicated for primary indication for morbid obesity, but this can also be used for the revision of a LSG. Here, a full-thickness suture is performed with a special suture device (Apollo Overstich) using a single or double row suture vertically placed along the greater curvature. The suture is set interrupted, so that the secretion of the stomach can completely reach the duodenum. The first documented clinical series in Germany was carried out by our group at the Charité, Virchow Clinic, Berlin. The first patient had a BMI of $45 \mathrm{~kg} / \mathrm{m}^{2}$ and a huge fat apron and a giant incisional hernia due to multiple abdominal surgeries $(n=14)$. Two attempts of laparoscopic and open bariatric operation were aborted due to adhesions. The procedure took a total of 90 min with no complications (Figure 6) ${ }^{61}$. After six months was observed a weight reduction of $25 \%\left(\mathrm{BMI}=30.2 \mathrm{~kg} / \mathrm{m}^{2}\right)$. Further series in our institution are studying the indication of endosleeve as a first step for patients super-super obese (BMI over $60 \mathrm{~kg} / \mathrm{m}^{2}$ ) and for high risk patients with cardiovascular impairment as a definitive procedure, and for renal transplant recipients with morbid obesity as a preparation for the kidney transplant.

The available published studies show very good results, but the number of patients is still low ${ }^{62,63}$. In the longest follow-up study ( $n=25$, observation period one year) the body weight was reduced in $19 \%$ and the EWL in $54 \% 64$. No complications were documented. In comparison to LSG, the gastric blood supply and innervation are preserved. The process can be reversible in the first two weeks. It is possible that ESG can be indicated for very high BMI in the concept of two step procedure instead of LSG, as performed in our first series in Charité, Berlin. The technique can also be indicated after an initial reduction in weight and applied secondarily during RYGB 24,65

Endoscopic Apollo revision after LSG can be also possible for treatment failure, that occurs in up to $20 \%$ of cases due to insufficient weight loss or weight regain ${ }^{16,17}$. If large diameter of the sleeve is diagnosed by gastric radiologic volumetry, a so-called endoscopic re-sleeving can be carried out ${ }^{58,59}$. The literature for endoscopic re-sleeving a failed LSG is still scarce.

\section{CONCLUSION}

The growing incidence of bariatric surgery is associated with an increase in the importance in revisional techniques. Inadequate weight loss or weight regain are the most common indication for revision and conversion. Preliminary results justify the use of RYGB as conversion procedure of choice. Alternatively, endoscopic procedures with low risk can be used with less morbidity and mortality, although long-term results are still not available.

\section{REFERENCES}

1.Mendis S. Global status report on noncommunicable diseases 2014: World Health Organization; 2014.

2.Sjöström L. Review of the key results from the Swedish Obese Subjects (SOS) trial - a prospective controlled intervention study of bariatric surgery. J Intern Med 2013;273:219-34. doi:10.1111/joim.12012.

3.Puzziferri N, Roshek TB, Mayo HG, Gallagher R, Belle SH, Livingston EH. Long-term follow-up after bariatric surgery: a systematic review. JAMA 2014;312:934-42. doi:10.1001/jama.2014.10706.

4.Chang S-H, Stoll CRT, Song J, Varela JE, Eagon CJ, Colditz GA. Theeffectiveness andrisksofbariatricsurgery:anupdated systematicreviewandmeta-analysis, 2003-2012.JAMASurg2014;149:275-87.doi:10.1001/jamasurg.2013.3654.

5.Angrisani L, Santonicola A, lovino P, Formisano G, Buchwald H, Scopinaro N. BariatricSurgeryWorldwide2013.ObesSurg2015;25:1822-32.doi:10.1007/ s11695-015-1657-z.

6.Montero PN, Stefanidis D, Norton HJ, Gersin K, Kuwada T. Reported excess weight loss after bariatric surgery could vary significantly depending on calculation method: a plea for standardization. Surg Obes Relat Dis 2011;7:531-4. doi:10.1016/j.soard.2010.09.025.

7.Karmali S, Brar B, Shi X, Sharma AM, Gara C de, Birch DW. Weight recidivism post-bariatric surgery: a systematic review. Obes Surg 2013;23:1922-33. doi:10.1007/s11695-013-1070-4.

8.Brolin RE, Kenler HA, Gorman RC, Cody RP. The dilemma of outcome assessment after operations for morbid obesity. Surgery 1989;105:337-46.

9.Reinhold RB. Critical analysis oflong termweightlossfollowing gastric bypass. Surg Gynecol Obstet 1982;155:385-94.

10.Christou NV, Look D, Maclean LD. Weight gain after short- and long-limb gastric bypass in patients followed for longer than 10 years. Ann Surg 2006:244:734-40. doi:10.1097/01.sla.0000217592.04061.d5.

11.StrohC, WeinerR, WolffS, KnollC, MangerT. Revisions-und "Redo"-Eingriffe in derAdipositas-und metabolischen Chirurgie:Datenanalyse des German BariatricSurgery Registry2005-2012.Chirurg2015;86:346-54.doi:10.1007/ s00104-014-2762-6.

12.Brethauer SA, Kothari S, Sudan R, Williams B, English WJ, Brengman M, et al. Systematic review on reoperative bariatric surgery: American Society for Metabolic and Bariatric Surgery Revision Task Force. Surg Obes Relat Dis 2014;10:952-72. doi:10.1016/j.soard.2014.02.014.

13.Mann JP, Jakes AD, Hayden JD, Barth JH. Systematic review of definitions of failurein revisional bariatricsurgery.ObesSurg2015;25:571-4.doi:10.1007/ s11695-014-1541-2.

14. Pekkarinen T, Mustonen $\mathrm{H}$, Sane T, Jaser $\mathrm{N}$, Juuti A Leivonen M. Long-Term Effect of Gastric Bypass and Sleeve Gastrectomy on Severe Obesity: Do Preoperative Weight Loss and Binge Eating Behavior Predict the Outcome of Bariatric Surgery? Obes Surg 2016. doi:10.1007/s11695-016-2090-7.

15.Buchwald H, Oien DM. Metabolic/bariatric surgery worldwide 2011. Obes Surg 2013;23:427-36. doi:10.1007/s11695-012-0864-0.

16. Himpens J, Dobbeleir J, Peeters G. Long-term results of laparoscopic sleeve gastrectomy for obesity. Ann Surg 2010;252:319-24. doi:10.1097/ SLA.0b013e3181e90b31. 
17.BohdjalianA, LangerFB, Shakeri-LeidenmühlerS, Gfrerer L, LudvikB, Zacher J, Prager G. Sleeve gastrectomy as sole and definitive bariatric procedure: 5-year results for weight loss and ghrelin. Obes Surg 2010;20:535-40. doi:10.1007/s11695-009-0066-6

18.DuPree CE, Blair K, Steele SR, Martin MJ. Laparoscopic sleeve gastrectomy in patients with preexisting gastroesophageal reflux disease: A national analysis. JAMA Surg 2014;149:328-34. doi:10.1001/jamasurg.2013.4323.

19.Cheung D, Switzer NJ, Gill RS, Shi X, Karmali S. Revisional bariatric surgery following failed primary laparoscopic sleeve gastrectomy: a systematic review. Obes Surg 2014;24:1757-63. doi:10.1007/s11695-014-1332-9.

20.Shimizu H, Annaberdyev S, Motamarryl, Kroh M, Schauer PR, Brethauer SA Revisional bariatric surgery for unsuccessful weight loss and complications. Obes Surg 2013;23:1766-73. doi:10.1007/s11695-013-1012-1.

21.Langer FB, Bohdjalian A, Shakeri-Leidenmühler S, Schoppmann SF, Zacher J. Prager G. Conversion from sleeve gastrectomy to Roux-en-Y gastric bypass--indicationsand outcome.ObesSurg2010;20:835-40.doi:10.1007/ s11695-010-0125-z.

22.Carmeli I, Golomb I, Sadot E, Kashtan H, Keidar A. Laparoscopic conversion of sleeve gastrectomyto a biliopancreatic diversion with duodenal switchor a Roux-en-Y gastric bypass due to weight loss failure: our algorithm. Surg Obes Relat Dis 2015:11:79-85. doi:10.1016/j.soard.2014.04.012.

23.Abdemur A, Han S-M, Lo Menzo E, Szomstein S, Rosenthal R. Reasons and outcomes of conversion of laparoscopic sleeve gastrectomy to Roux-en-Y gastric bypass for nonresponders. Surg Obes Relat Dis 2016;12:113-8. doi:10.1016/j.soard.2015.04.005.

24.GautierT, SarcherT, Contival N, Le RouxY, Alves A. Indications and mid-term results of conversion from sleeve gastrectomy to Roux-en-Y gastric bypass. Obes Surg 2013;23:212-5. doi:10.1007/s11695-012-0782-1.

25.Tice JA, Karliner L, Walsh J, Petersen AJ, Feldman MD. Gastric banding or bypass? A systematic review comparing the two most popular bariatric procedures.AmJMed2008;121:885-93.doi:10.1016/j.amjmed.2008.05.036

26.Spivak H, Abdelmelek MF, Beltran OR, Ng AW, Kitahama S. Long-term outcomes of laparoscopic adjustable gastric banding and laparoscopic Roux-en-YgastricbypassintheUnitedStates.Surg Endosc2012;26:1909-19. doi:10.1007/s00464-011-2125-z

27.Chevallier J-M, Zinzindohoué F, Douard R, Blanche J-P, Berta J-L, Altman J-J, Cugnenc $\mathrm{P}-\mathrm{H}$. Complications after laparoscopic adjustable gastric banding for morbid obesity: experience with 1,000 patients over 7 years. Obes Surg 2004:14:407-14 doi:10.1381/096089204322917954

28.Egberts K, Brown WA, O'Brien PE. Systematic review of erosion after laparoscopic adjustable gastric banding. Obes Surg 2011;21:1272-9. doi:10.1007/s11695-011-0430-1.

29.Aarts EO, van Wageningen B, Berends F, Janssen I, Wahab P, Groenen M Intragastric band erosion: experiences with gastrointestinal endoscopic removal.WorldJGastroenterol2015;21:1567-72.doi:10.3748/wjg.v21.i5.1567.

30.Elnahas A, Graybiel K, Farrokhyar F, Gmora S, Anvari M, Hong D. Revisional surgery after failed laparoscopic adjustable gastric banding: a systematic review. Surg Endosc 2013:27:740-5. doi:10.1007/s00464-012-2510-2

31.MasonEE. Vertical bandedgastroplastyforobesity.ArchSurg 1982;117:701-6

32.Trus TL, Pope GD, Finlayson SRG. National trends in utilization and outcomes of bariatric surgery. Surg Endosc 2005;19:616-20. doi:10.1007/s00464004-8827-8

33.Scozzari G, Toppino M, Famiglietti F, Bonnet G, Morino M. 10-year followup of laparoscopic vertical banded gastroplasty: good results in selected patients. Ann Surg 2010;252:831-9. doi:10.1097/SLA.0b013e3181fd35b0.

34.Suter M, Ralea S, Millo P, Allé JL. Laparoscopic Roux-en-Y Gastric bypass after failed vertical banded gastroplasty: a multicenter experience with 203 patients. Obes Surg 2012;22:1554-61. doi:10.1007/s11695-012-0692-2.

35.Apers JA, Wens $C$, van Vlodrop V, Michiels $M$, Ceulemans $R$, van Daele $\mathrm{G}$, Jacobs I. Perioperative outcomes of revisional laparoscopic gastric bypass after failed adjustable gastric banding and after vertical banded gastroplasty:experiencewith 107 casesand subgroupanalysis. Surg Endosc 2013:27:558-64. doi:10.1007/s00464-012-2483-1.

36.David MB, Abu-Gazala S, Sadot E, Wasserberg N, Kashtan H, Keidar A Laparoscopic conversion of failed vertical banded gastroplasty to Rouxen-Y gastric bypass or biliopancreatic diversion. Surg Obes Relat Dis 2015;11:1085-91. doi:10.1016/j.soard.2015.01.026.

37. Schouten $R$, van Dielen, Francois $M H$ van Gemert WG, Greve JWM. Conversion of vertical banded gastroplasty to Roux-en- $Y$ gastric bypass resultsin restoration of the positiveeffecton weightlossand co-morbidities: evaluation of 101 patients. Obes Surg 2007:17:622-30.

38.van Wezenbeek MR, Smulders JF, de Zoete, J P J G M, Luyer MD, van Montfort G, Nienhuijs SW. Long-Term Results of Primary Vertical Banded Gastroplasty.ObesSurg2015;25:1425-30.doi:10.1007/s11695-014-1543-0.

39.van Gemert WG, van Wersch MM, Greve JW, Soeters PB. Revisional surgery after failed vertical banded gastroplasty: restoration of vertical banded gastroplasty or conversion to gastric bypass. Obes Surg 1998:8:21-8. doi:10.1381/096089298765555006

40.Gagné DJ, Dovec E, Urbandt JE. Laparoscopic revision of vertical banded gastroplasty to Roux-en-Y gastric bypass: outcomes of 105 patients. Surg Obes Relat Dis 2011;7:493-9. doi:10.1016/j.soard.2010.10.014.

41.Marsk R, Jonas E, Rasmussen F, Näslund E. Nationwide cohort study of post-gastric bypass hypoglycaemia including 5,040 patients undergoing surgeryforobesityin 1986-2006inSweden. Diabetologia2010;53:2307-11. doi:10.1007/s00125-010-1798-5.
42.Foster-SchubertKE. Hypoglycemiacomplicating bariatricsurgery:incidence and mechanisms. Curr Opin Endocrinol Diabetes Obes 2011;18:129-33. doi:10.1097/MED.0b013e32834449b9.

43.Lee CJ, Wood GC, Lazo M, Brown TT, Clark JM, Still C, Benotti P. Risk of postgastric bypass surgery hypoglycemia in nondiabetic individuals: A single center experience. Obesity (Silver Spring) 2016:24:1342-8. doi:10.1002/ oby. 21479 .

44.Rariy CM, Rometo D, Korytkowski M. Post-Gastric Bypass Hypoglycemia. Curr Diab Rep 2016:16:19. doi:10.1007/s11892-015-0711-5.

45.Wiesli P, Brandle M, Schmid C, Krahenbuhl L, Furrer J, Keller U, et al. Selective arterial calcium stimulation and hepatic venous sampling in the evaluation of hyperinsulinemic hypoglycemia: potential and limitations. J Vasc Interv Radiol 2004;15:1251-6. doi:10.1097/01.RVI.0000140638.55375.1E.

46.Campos GM, Ziemelis M, Paparodis R, Ahmed M, Davis DB. Laparoscopic reversal of Roux-en-Y gastric bypass: technique and utility for treatment of endocrinecomplications.Surg ObesRelatDis2014;10:36-43.doi:10.1016/j. soard.2013.05.012

47.McLaughlin T, Peck M, Holst J, Deacon C. Reversible hyperinsulinemic hypoglycemia after gastric bypass: a consequence of altered nutrient delivery.JClinEndocrinolMetab2010:95:1851-5.doi:10.1210/jc.2009-1628.

48.ChattranukulchaiShantavasinkulP, TorquatiA, CorsinoL. Post-GastricBypass Hypoglycemia:AReview.ClinEndocrinol(Oxf)2016.doi:10.1111/cen.13033.

49.Service GJ, Thompson GB, Service FJ, Andrews JC, Collazo-Clavell ML, Lloyd RV.Hyperinsulinemichypoglycemiawithnesidioblastosisaftergastric-bypass surgery. N Engl J Med 2005;353:249-54. doi:10.1056/NEJMoa043690.

50.Alvarez GC, Faria EN, Beck M, Girardon DT, Machado AC. Laparoscopic spleen-preserving distal pancreatectomy as treatment for nesidioblastosis after gastric bypass surgery. Obes Surg 2007;17:550-2. doi:10.1007/ s11695-007-9096-0.

51.ZorronR, KrenzienF,BenzingC,PratschkeJ.One-AnastomsisJEJ-Interposition with Gastric-Resection for Postbypass Hypoglycemia: The Branco-Zorron Procedure. Dreiländertreffen Heidelberg 2016

52.BenzingC,KrenzienF,JunghansT,BotheC,PratschkeJ,ZorronR.Intraabdominal Trocar-Free Vacuum Liver Retractor for Laparoscopic Sleeve Gastrectomy (Video). Obes Surg 2016. doi:10.1007/s11695-016-2245-6.

53.Jiménez A, Casamitjana R, Flores L, Viaplana J, Corcelles R, Lacy A, Vidal J. Long-term effects of sleeve gastrectomy and Roux-en-Y gastric bypass surgery on type 2 diabetes mellitus in morbidly obese subjects. Ann Surg 2012:256:1023-9. doi:10.1097/SLA.0b013e318262ee6b.

54.Cooper TC, Simmons EB, Webb K, Burns JL, Kushner RF. Trends in Weight Regain Following Roux-en-Y Gastric Bypass (RYGB) Bariatric Surgery. Obes Surg 2015;25:1474-81. doi:10.1007/s11695-014-1560-z.

55.Kumar N, Thompson CC. Comparison of a superficial suturing device with a full-thickness suturing device for transoral outlet reduction (with videos). Gastrointest Endosc 2014;79:984-9. doi:10.1016/j.gie.2014.02.006.

56.Thompson CC, Chand B, Chen YK, Demarco DC, Miller L, Schweitzer M, et al. Endoscopic suturing for transoral outlet reduction increases weight loss after Roux-en-Y gastric bypass surgery. Gastroenterology 2013;145:129. doi:10.1053/j.gastro.2013.04.002

57.Kumar N, Thompson CC. Transoral outlet reduction for weight regain after gastricbypass:long-termfollow-up.GastrointestEndosc2015.doi:10.1016/j. gie.2015.08.039.

58.Amor IB, Debs T, Martini F, Elias B, Kassir R, Gugenheim J. Laparoscopic Conversion of a Sleeve Gastrectomy to the Roux-en-Y Gastric Bypass. Obes Surg 2015;25:1556-7. doi:10.1007/s11695-015-1749-9.

59.Noel P, Nedelcu M, Nocca D, Schneck A-S, Gugenheim J, lannelli A, Gagner M. Revised sleeve gastrectomy: another option for weight loss failure after sleeve gastrectomy. Surg Endosc 2014;28:1096-102. doi:10.1007/ s00464-013-3277-9.

60.Abu Dayyeh BK, Rajan E, Gostout CJ. Endoscopic sleeve gastroplasty: a potentialendoscopicalternativetosurgicalsleevegastrectomyfortreatment ofobesity.GastrointestEndosc2013;78:530-5.doi:10.1016/j.gie.2013.04.197.

61.Zorron R, Krenzien F, Ucta C, Veltzke-Schlieker W, Adler A. Endoscopic Sleeve Gastroplasty ESG: First German Clinical Experience. 46th Congress DGE-BV 2016.

62.Sharaiha RZ, Kedia P, Kumta N, DeFilippis EM, Gaidhane M, Shukla A, et al. Initial experience with endoscopic sleeve gastroplasty: technical success and reproducibility in the bariatric population. Endoscopy 2015:47:164-6. doi:10.1055/s-0034-1390773.

63.Lopez-Nava G, Galvão MP, da Bautista-Castaño I, Jimenez A, Grado T de Fernandez-Corbelle JP. Endoscopic sleeve gastroplasty for the treatment of obesity. Endoscopy 2015;47:449-52. doi:10.1055/s-0034-1390766.

64.Lopez-Nava G, Galvao M, Bautista-Castañol, Fernandez-CorbelleJP, Trell M. Endoscopic sleeve gastroplasty with 1-year follow-up: factors predictive of success. Endosc Int Open 2016;4:7. doi:10.1055/s-0041-110771.

65.Mognol P, Chosidow D, Marmuse J-P. Laparoscopic sleeve gastrectomy as an initial bariatric operation for high-risk patients: initial results in 10 patients. Obes Surg 2005;15:1030-3. doi:10.1381/0960892054621242

66.ZorronR, BotheC,JunghansT,PratschkeJ,Benzing C, KrenzienF.[Conversional and endoscopic procedures following bariatric surgery]. Chirurg. 2016 Oct;87(10):857-64. doi: 10.1007/s00104-016-0277-z. German. PubMed PMID: 27566189. 
In the article "FROM COMPLEX EVOLVING TO SIMPLE: CURRENT REVISIONAL AND ENDOSCOPIC PROCEDURES FOLLOWING BARIATRIC SURGERY", with the number of DOI: /10.1590/0102-6720201600S10031, published in the periodical Arquivos Brasileiros de Cirurgia Digestiva, 29 (Suppl 1): 128- 133, on page 128:

Where it read:

Received for publication: 02/16/2016

Accepted for publication: 6/2/2016

Read:

Received for publication: 8/16/2016

Accepted for publication: 02/10/2016

On page 132, it was added after completion:

\section{ACKNOWLEDGMENTS:}

This review has been published in part in the German language to disseminate the current topic to the public who speaks foreign languages more widely.

On page 133, a reference number 66 was added:

66. Zorron R, Bothe C, Junghans T, Pratschke J, Benzing C, Krenzien F. [Conversational and endoscopic procedures after bariatric surgery]. Chirurg. 2016 out; 87 (10): 857-64. Doi: 10.1007 / s00104-016-0277-z. German. PubMed PMID: 27566189. 